Buletin Ilmiah Math. Stat. dan Terapannya (Bimaster)

Volume 09, No. 1 (2020), hal 239 - 244.

\title{
PENDEKATAN METODE BAYESIAN GELF PADA MODEL SURVIVAL EKSPONENSIAL UNTUK MENENTUKAN PREMI TUNGGAL PADA ASURANSI
}

\author{
Santi, Shantika Martha, Setyo Wira Rizki
}

\begin{abstract}
INTISARI
Model survival didefinisikan sebagai suatu distribusi probabilitas untuk variabel random yang berkaitan dengan usia serta ketahanan suatu produk ataupun jiwa. Model survival dalam penelitian ini membahas tentang fungsi ketahanan hidup dari suatu individu. Model survival diaplikasikan untuk mendapatkan nilai premi asuransi jiwa dwiguna. Premi asuransi dwiguna didapatkan dengan pendekatan metode Bayesian. Metode Bayesian adalah metode yang digunakan untuk menentukan distribusi posterior. Langkah yang dilakukan untuk mendapatkan distribusi posterior yaitu mengalikan fungsi likelihood dengan distribusi prior. Kemudian diperoleh distribusi posterior yang digunakan untuk mengestimasi metode Bayesian GELF (General Entropy Loss Function) pada model survival, dan diaplikasikan ke APV (Actuarial Present Value) asuransi jiwa dwiguna. Berdasarkan penelitian diketahui bahwa premi asuransi jiwa dwiguna pada seseorang berusia 30 tahun dengan jangka waktu 10 tahun didapat harga premi sebesar Rp78.742.900.
\end{abstract}

Kata kunci: Model survival, Metode Bayesian, Distribusi posterior.

\section{PENDAHULUAN}

Asuransi adalah perjanjian antara dua belah pihak, yaitu perusahaan asuransi dan pemegang polis, yang menjadi dasar bagi penerimaan premi oleh perusahaan asuransi sebagai imbalan. Perusahaan asuransi berkewajiban memberikan pembayaran yang didasarkan pada meninggalnya tertanggung atau pembayaran yang didasarkan pada hidupnya tertanggung dengan manfaat yang besarnya telah ditetapkan [1]. Sedangkan tertanggung diwajibkan membayar sejumlah uang yang telah disepakati sesuai kontrak kepada penanggung yang biasa disebut premi [2]. Pembayaran premi asuransi dapat dilakukan pada waktu kontrak asuransi disetujui, selanjutnya tidak ada pembayaran lagi disebut premi tunggal bersih [3]. Di Indonesia terdapat beberapa jenis asuransi jiwa yaitu asuransi dengan manfaat bertingkat (varying benefit insurance), asuransi jiwa dwiguna (endowment insurance), asuransi jiwa berjangka $n$-tahun (n-year term insurance), dan asuransi jiwa seumur hidup (whole life insurance). Asuransi yang digunakan dalam penelitian ini menggunakan asuransi jiwa dwiguna.

Asuransi jiwa dwiguna memiliki dua manfaat yaitu manfaat dari asuransi jiwa berjangka $k$-tahun dan asuransi jiwa dwiguna murni. Pada Asuransi jiwa dwiguna manfaat kematian akan diberikan seketika pada saat kematian apabila peserta asuransi meninggal sebelum $k$-tahun atau apabila masih hidup sampai dengan $k$-tahun [2]. Asuransi jiwa terdapat risiko yang mungkin timbul terutama terletak pada unsur waktu. Unsur waktu inilah yang sangat sulit diperkirakan sehingga pada penelitian ini akan menggunakan fungsi survival. Fungsi survival adalah analisis daya tahan hidup (survival) suatu unit atau individu. Analisis survival memerlukan data yang merupakan waktu survival dari suatu individu. Pada survival terdapat dua model untuk menganalisis data survival yaitu model parametrik dan nonparametrik. Model parametrik terdiri dari distribusi eksponensial, distribusi Weibull, distribusi Lognormal dan distribusi Gamma. Sedangkan model non-parametrik merupakan model yang digunakan untuk mengestimasi parameter terdiri dari dua pendekatan yaitu pendekatan klasik (classical approach) dan pendekatan Bayesian atau yang dikenal dengan pendekatan metode Bayesian [4]. Ada beberapa pendekatan dalam metode Bayesian yang digunakan untuk mengestimasi parameter lain general non-informatif prior, Lindley approximation, dan general entropy loss function (GELF). 
Penelitian ini bertujuan menentukan harga premi dwiguna menggunakan pendekatan metode Bayesian GELF dengan model survival berdistribusi eksponensial. Langkah yang dilakukan adalah menentukan fungsi kepadatan peluang dan fungsi survival. Selanjutnya menentukan distribusi prior untuk mengestimasi parameter $\theta$ pada model survival. Kemudian menentukan distribusi posterior yang diperoleh dari pengalian antara fungsi likelihood dan distribusi prior. Selanjutnya mengestimasi metode Bayesian GELF pada model survival yang akan diterapkan pada model APV asuransi jiwa dwiguna.

\section{FUNGSI WAKTU SURVIVAL}

Waktu survival $(T)$ merupakan variabel random non-negatif yang mewakili kehidupan individu dari beberapa populasi dengan variabel random kontinu dalam interval $[0, \infty)$ atau dapat diartikan dalam survival yaitu waktu $t$ dimana $t \geq 0$. Waktu survival dapat dinyatakan dalam 3 fungsi yaitu fungsi kepadatan peluang $f(t)$, fungsi survival $s(t)$ dan fungsi hazard $h(t)$. Fungsi kepadatan peluang atau PDF (Probability density function) adalah peluang suatu individu mengalami suatu kejadian. Jika $f(t)$ merupakan fungsi densitas peluang maka fungsi distribusi kumulatif $F(t)$ yaitu:

$$
F(t)=\operatorname{Pr}(T \leq t)=\int_{0}^{t} f(t) d t, t \geq 0
$$

Fungsi survival $s(t)$ didefinisikan sebagai peluang seseorang dapat bertahan hidup hingga usia $t$ tahun dengan $t \geq 0$. Fungsi survival $s(t)$ dapat dinyatakan sebagai berikut:

$$
s(t)=\operatorname{Pr}(T \geq t)=\int_{t}^{\infty} f(t) d t, t \geq 0
$$

\section{DISTRIBUSI EKSPONENSIAL}

Distribusi eksponensial merupakan distribusi yang digunakan untuk menguji ketahanan hidup dimana distribusi eksponensial adalah salah satu metode statistik yang dikembangkan secara ekstensif [5]. Distribusi eksponensial dinotasikan $T \sim \operatorname{Exponensial~}(\theta)$ dimana $T$ merupakan variabel random yang mengikuti distribusi eksponensial dengan parameter $\theta[4]$. Fungsi kepadatan peluang untuk distribusi eksponensial adalah sebagai berikut:

$$
f(t ; \theta)=\theta e^{-\theta t}, t \geq 0 ; \theta \geq 0
$$

Fungsi distribusi kumulatif untuk distribusi eksponensial adalah sebagai berikut:

$$
F(t ; \theta)=1-e^{-\theta t}, t \geq 0 ; \theta \geq 0
$$

Fungsi survival untuk distribusi eksponensial adalah sebagai berikut:

$$
s(t ; \theta)=e^{-\theta t}, t \geq 0 ; \theta \geq 0
$$

\section{METODE BAYESIAN}

Metode Bayesian adalah metode yang digunakan untuk menentukan distribusi posterior. Metode Bayesian memandang parameter $\theta$ sebagai variabel yang menggambarkan pengetahuan awal tentang parameter sebelum pengamatan dilakukan dan dinyatakan dalam suatu distribusi yang disebut dengan distribusi prior [6]. Sebelum menentukan distribusi posterior ada beberapa yang harus ditentukan terlebih dahulu yaitu (1) pembentukan fungsi likelihood dan (2) penentuan distribusi prior. Langkahlangkah yang dilakukan adalah sebagai berikut:

\section{Pembentukan Fungsi Likelihood}

Fungsi likelihood memiliki peran penting dalam metode Bayesian. Fungsi likelihood adalah salah syarat untuk mendapatkan distribusi posterior. Fungsi likelihood digunakan untuk melakukan penaksiran parameter yang tidak diketahui [6]. Berikut diperoleh fungsi likelihood dari distribusi 
eksponensial yakni sebagai berikut:

$$
\begin{aligned}
L\left(t_{j} ; \theta\right) & =\prod_{j=1}^{n} f\left(t_{j} ; \theta\right) \\
& =\prod_{j=1}^{n} \theta e^{-\theta t_{j}} \\
& =\theta^{n} e^{-\theta \sum_{j=1}^{n} t_{j}}
\end{aligned}
$$

\section{Penentuan Distribusi Prior}

Distribusi Gamma telah tetapkan sebagai distribusi prior. Peneliti memilih distribusi Gamma karena distribusi Gamma memiliki kesamaan dengan distribusi eksponensial. Kesamaan dapat dilihat dari bentuk distribusi Gamma, yaitu pada saat $\alpha=1$ distribusi Gamma akan membentuk distribusi khusus dengan distribusi eksponensial dengan parameter $\theta$ dimana $0<\theta<\infty$. Misalkan $\theta$ variabel dan parameternya adalah $\alpha$ dan $\beta$. Fungsi kepadatan peluang distribusi Gamma sebagai berikut:

$$
f(\theta)=\frac{\beta^{\alpha}}{\Gamma(\alpha)} \theta^{\alpha-1} e^{-\beta \theta} ; \alpha>0, \beta>0, \Gamma(\alpha) \neq 0
$$

Berdasarkan Persamaan (7) maka dipilihlah distribusi Gamma sebagai distribusi prior.

\section{Penentuan Distribusi Posterior}

Setelah mencari fungsi likelihood dan menentukan distribusi prior maka dapat dicari distribusi posteriornya. Distribusi posterior dapat ditentukan dengan perkalian antara fungsi likelihood dengan distribusi prior. Distribusi posterior dapat dinyatakan sebagai berikut:

$$
f\left(\theta \mid t_{j}\right)=\frac{f(\theta) L\left(t_{j}, \theta\right)}{\int_{0}^{\infty} f(\theta) L\left(t_{j}, \theta\right) d \theta}, \theta \geq 0
$$

dimana $f\left(\theta \mid t_{j}\right)$ merupakan distribusi posterior, $f(\theta)$ adalah distribusi prior, sedangkan $L\left(t_{j}, \theta\right)$ ialah fungsi likelihood. Berdasarkan Persamaan (6), (7), dan (8) maka diperoleh fungsi kepadatan peluang distribusi posterior yaitu sebagai berikut:

$$
f\left(\theta \mid t_{j}\right)=\frac{\left(\beta+\sum_{j=1}^{n} t_{j}\right)^{\alpha+n} \theta^{\alpha+n-1} e^{-\theta\left(\beta+\sum_{j=1}^{n} t_{j}\right)}}{\Gamma(\alpha+n)}, \theta \geq 0 ; \alpha>0 ; \beta>0 ; \Gamma(\alpha+n) \neq 0
$$

Dari Persamaan (9), maka diperoleh distribusi posterior yang merupakan distribusi Gamma dengan parameter $(\alpha+n)$ dan $\left(\beta+\sum_{j=1}^{n} t_{j}\right)$.

\section{METODE BAYESIAN GELF}

Menggunakan General Entropy Loss Function (GELF) dimana Loss Function didefinisikan [7]:

$$
\mathcal{L}\left(\theta, \hat{\theta}_{B G}\right)=\left(\frac{\hat{\theta}_{B G}}{\theta}\right)^{\alpha_{1}}-\alpha_{1} \ln \left(\frac{\hat{\theta}_{B G}}{\theta}\right)-1, \theta \neq 0
$$

dimana $\hat{\theta}$ merupakan estimator Bayesian GELF untuk parameter $\theta$.

Estimasi parameter $\theta$ diperoleh dengan meminimumkan ekspektasi Loss Function [7]. Ekspektasi Loss Function diperoleh sebagai berikut:

$$
\hat{\theta}_{B G}=E\left(\theta^{-\alpha_{1}}\right)
$$


Berdasarkan Persamaan (10) maka estimasi parameter dengan metode Bayesian GELF menggunakan prior Gamma adalah sebagai berikut:

$$
\begin{aligned}
\hat{\theta}_{B G}=\int_{0}^{\infty} \theta^{-\alpha_{1}} \frac{\left.\left(\beta+\sum_{j=1}^{n} t_{j}\right)^{\alpha+n} \theta^{\alpha+n-1} e^{-\theta\left(\beta+\sum_{j=1}^{n} t_{j}\right.}\right)}{\Gamma(\alpha+n)} d \theta \\
\left.\hat{\theta}_{B G}=\frac{\left(\beta+\sum_{j=1}^{n} t_{j}\right)^{\alpha+n}\left(\frac{1}{\Gamma(\alpha+n)}\right){ }^{\alpha+n-\alpha_{1}}}{\beta+\sum_{j=1}^{n} t_{j}}\right)_{0}^{\infty} u^{\alpha+n-1-\alpha_{1}} e^{-u} d u \\
\hat{\theta}_{B G}=\frac{\left(\beta+\sum_{j=1}^{n} t_{j}\right)^{\alpha+n}}{\Gamma(\alpha+n)}\left(\frac{1}{\beta+\sum_{j=1}^{n} t_{j}}\right)^{\alpha+n}\left(\frac{1}{\beta+\sum_{j=1}^{n} t_{j}}\right)^{-\alpha_{1}} \Gamma\left(\alpha+n-\alpha_{1}\right) \\
\hat{\theta}_{B G}=\frac{\Gamma(\alpha+n-\alpha)}{\Gamma(\alpha+n)}\left(\frac{1}{\beta+\sum_{j=1}^{n} t_{j}}\right)^{-\alpha_{1}}
\end{aligned}
$$

Berdasarkan dari Persamaan (11) diperolehlah estimasi parameter dengan metode Bayesian GELF untuk fungsi survival ialah:

$$
\hat{s}(t ; \hat{\theta})_{B G}=e^{-\hat{\theta}_{B G} t}=e^{-\left[\left(\frac{\Gamma\left(\alpha+n-\alpha_{1}\right)}{\Gamma(\alpha+n)}\right)\left(\frac{1}{\beta+\sum_{j=1}^{n} t_{j}}\right)^{-\alpha_{1}}\right] t}
$$

\section{MODEL PELUANG HIDUP DAN PELUANG MENINGGAL DENGAN ESTIMASI PARAMETER}

Pemodelan APV dalam aktuaria menggunakan fungsi peluang hidup dan peluang meninggal. Peluang hidup dan peluang meninggal seseorang akan menjadi salah satu faktor yang mempengaruhi asuransi jiwa dimana usia seseorang akan mempengaruhi pada pembayaran premi dalam asuransi. Peluang hidup seseorang dinotasikan $p_{t}$ yang menyatakan peluang seseorang yang berusia $t$ tahun akan bertahan hidup hingga usia $(t+1)$ tahun [2]. Diperoleh fungsi peluang hidup dan meninggal menggunakan metode Bayesian GELF dengan fungsi survival sebagai berikut:

$$
\left(p_{t}\right)_{B G}=e^{-\left(\left(\frac{\Gamma\left(\alpha+n-\alpha_{1}\right)}{\Gamma(\alpha+n)}\right)\left(\frac{1}{\beta+\sum_{j=1}^{n} t_{j}}\right)^{-\alpha_{1}}\right)}
$$

Sedangkan peluang meninggal seseorang dinotasikan $q_{t}$. Berikut diperolah peluang seseorang akan meninggal dunia yaitu:

$$
\left(q_{t}\right)_{B G}=1-e^{\left.-\left(\frac{\Gamma\left(\alpha+n-\alpha_{1}\right)}{\Gamma(\alpha+n)}\right)\left(\frac{1}{\beta+\sum_{j=1}^{n} t_{j}}\right)^{-\alpha_{1}}\right)}
$$




\section{MODEL APV PREMI TUNGGAL DWIGUNA}

Asuransi jiwa dwiguna dengan jumlah unit pembayaran pada akhir tahun kematian merupakan pengkombinasian antara asuransi jiwa berjangka $m$-tahun dengan asuransi jiwa dwiguna murni. Diperoleh model APV pada premi tunggal dwiguna sebagai berikut:

a) Model premi asuransi jiwa berjangka

$$
\begin{aligned}
& A_{t: m}^{\prime}=B \sum_{k=0}^{m-1} v^{k+1}\left({ }_{k} p_{t}\right)_{B G}\left(q_{t+k}\right)_{B G} \\
& A_{t: m}^{\prime}=B \sum_{k=0}^{m-1}\left(\frac{1}{1+i}\right)^{k+1} e^{\left.-\left(\frac{\Gamma\left(\alpha+n-\alpha_{1}\right)}{\Gamma(\alpha+n)}\right)\left(\frac{1}{\beta+\sum_{j=1}^{n} t_{j}}\right)^{-\alpha_{1}}\right)} 1-e^{\left(-\left(\frac{\Gamma\left(\alpha+n-\alpha_{1}\right)}{\Gamma(\alpha+n)}\right)\left(\frac{1}{\beta+\sum_{j=1}^{n} t_{j}}\right)^{-\alpha_{1}}\right)}
\end{aligned}
$$

b) Model premi asuransi jiwa dwiguna murni

$$
A_{t: m}^{\frac{1}{m}}=B v^{m}\left({ }_{m} p_{t}\right)_{B G}
$$

$$
A_{t: m}^{\frac{1}{1}}=B\left(\frac{1}{1+0.06}\right)^{m} e^{-\left(\left(\frac{\Gamma\left(\alpha+n-\alpha_{1}\right)}{\Gamma(\alpha+n)}\right)\left(\frac{1}{\beta+\sum_{j=1}^{n} t_{j}}\right)^{-\alpha_{1}}\right) m}
$$

c) Model premi asuransi jiwa dwiguna

$$
\begin{aligned}
& \bar{P}\left(A_{t: m}\right)=B\left(\left(\sum_{k=0}^{m-1} v^{k+1}\left({ }_{k} p_{t}\right)_{B G}\left(q_{t+k}\right)_{B G}\right)+\left(v^{m}\left({ }_{m} p_{t}\right)_{B G}\right)\right) \\
& \bar{P}\left(A_{t: m}\right)=B \sum_{k=0}^{m-1}\left(\frac{1}{1+i}\right)^{k+1} e^{\left.-\left(\frac{\Gamma\left(\alpha+n-\alpha_{1}\right)}{\Gamma(\alpha+n)}\right)\left(\frac{1}{\beta+\sum_{j=1}^{n} t_{j}}\right)^{-\alpha_{1}}\right)_{k}-\left(\left(\frac{\Gamma\left(\alpha+n-\alpha_{1}\right)}{\Gamma(\alpha+n)}\right)\left(\frac{1}{\beta+\sum_{j=1}^{n} t_{j}}\right)^{-\alpha_{1}}\right)+} \\
& \left(\frac{1}{1+i}\right)^{m} e^{-\left(\left(\frac{\Gamma\left(\alpha+n-\alpha_{1}\right)}{\Gamma(\alpha+n)}\right)\left(\frac{1}{\beta+\sum_{j=1}^{n} t_{j}}\right)^{-\alpha_{1}}\right)}
\end{aligned}
$$

dimana:

$$
\begin{array}{ll}
\bar{P}\left(A_{t: m}\right) & =\text { Premi tunggal asuransi jiwa dwiguna } m \text {-tahun untuk seseorang berusia } t \text { tahun } \\
A_{t: m} & =\text { Premi asuransi jiwa berjangka } m \text {-tahun untuk seseorang berusia } t \text { tahun } \\
A_{t: m} & =\text { Premi asuransi jiwa dwiguna murni } m \text {-tahun untuk seseorang berusia } t \text { tahun } \\
B & =\text { Manfaat yang diterima } \\
v^{k} & =\text { Faktor diskon pada periode } k \\
{ }_{k} p_{t} & =\text { Peluang seseorang berusia } t \text { tahun akan bertahan hidup sampai usia } t+k \text { tahun } \\
q_{t+k} & =\text { Peluang seseorang berusia } t+k \text { tahun akan meninggal pada usia } t+k+1 \text { tahun }
\end{array}
$$

\section{STUDI KASUS}

Pada penelitian ini studi kasus menggunakan usia seseorang yang berusia 1 sampai usia 50 tahun. Kemudian diuji data dengan uji Kolmogorov-Smirnov untuk mengetahui data berdistribusi eksponensial dan parameter. Setelah diketahui data berdistribusi eksponensial selanjutnya menentukan 
harga premi asuransi jiwa dwiguna dengan model survival eksponensial menggunakan pendekatan Bayesian GELF.

Perhitungan harga premi asuransi jiwa dwiguna seseorang yang mengikuti asuransi berusia 30 tahun dengan jangka waktu 10 tahun diketahui:

$$
\begin{aligned}
& B=\operatorname{Rp} 100.000 .000, n=50 ; \sum_{j=1}^{n} t_{j}=1275, \alpha=1, \beta=25,5 \mathrm{E}[\mathrm{T}]=25,5, \alpha_{1}=5, i=0,06 \\
& \bar{A}_{30: 10_{(B G)}}=\left(B\left[\sum_{k=0}^{10-1} v^{k+1}\left({ }_{k} p_{30}\right)_{(B G)}\left(q_{30+k}\right)_{(B G)}\right]+v^{10}{ }_{10} p_{30}\right)=78.742,900,94
\end{aligned}
$$

Harga premi asuransi jiwa dwiguna seseorang yang berusia 30 tahun dengan jangka waktu 10 tahun dapat dilihat pada Tabel 1 berikut:

Tabel 1 Harga Premi Dwiguna Usia 30 Tahun

\begin{tabular}{cccc}
\hline Jangka & $\begin{array}{c}\text { Premi Asuransi } \\
\text { Jiwa Berjangka }\end{array}$ & $\begin{array}{c}\text { Premi Asuransi Jiwa } \\
\text { Dwiguna Murni }\end{array}$ & $\begin{array}{c}\text { Premi Asuransi Jiwa } \\
\text { Dwiguna }\end{array}$ \\
\hline 10 Tahun & Rp56.351.860 & Rp22.391.040 & Rp78.742.900 \\
\hline
\end{tabular}

Dari Tabel 1 diperoleh masing-masing nilai APV dari premi asuransi jiwa dengan jangka waktu 10 tahun sebesar Rp56.351.860, sedangkan untuk asuransi jiwa dwiguna murni diperoleh sebesar Rp22.391.040, sehingga premi asuransi jiwa dwiguna diperoleh dengan menjumlahkan hasil dari premi asuransi berjangka dan premi asuransi dwiguna murni. Premi asuransi dwiguna yang dibayarkan untuk jangka waktu 10 tahun sebesar Rp78.742.900 dengan manfaat yang diterima sebesar 100 juta.

\section{KESIMPULAN}

Berdasarkan hasil penelitian dengan mengestimasi parameter menggunakan model survival berdistribusi eksponensial Bayesian GELF diperoleh model APV dari asuransi dwiguna. Model APV asuransi dwiguna diterapkan pada studi kasus seseorang yang berusia 30 tahun yang mengikuti asuransi jiwa dwiguna dalam jangka waktu 10 tahun. Benefit yang akan diterima nasabah adalah sebesar 100 juta, maka premi asuransi yang dibayarkan nasabah sebesar Rp78.742.900.

\section{DAFTAR PUSTAKA}

[1] Undang-Undang peransuransian UU RI Nomor 40, Sinar Grafika; Jakarta; 2014

[2] Bowers, N.L, Gerber HU, Hickman JC, Jones DA, Nesbitt CJ. Actuarial Mathematics. The Society of Actuaries. USA: 1997.

[3] Futami, T. Seimei Hoken Sugaku, Jokan. Japan: The Research of Life Insurance Welfare; 1992.

[4] Lee, E.T and Wang, J.W. Statistical Methods for Survival Data Analisis. Canada: John Wiley \& Sons Inc; 2003.

[5] Lawless, J.F. Statistical Methods for Survival Data Analysis. Canada: John Wiley and Sons; 1982.

[6] Bostald, W. Introduction to Bayesian Statistics. Amerika: John Wiley and Sons Inc; 2007.

[7] Shah, J.B., Patel, M.N. Bayes Estimation of a Two-Parameter Geometric Distribution under Multiply Type II Censoring. Hindawi. 2011 March;18(10);1-10.

SANTI

SHANTIKA MARTHA

SETYO WIRA RIZKI
Jurusan Matematika FMIPA Untan Pontianak, santivillata@gmail.com Jurusan Matematika FMIPA Untan Pontianak, shantika.martha@math.untan.ac.id Jurusan Matematika FMIPA Untan Pontianak, setyo.wirarizki@math.untan.ac.id 